\title{
Sporcularda kor kaslarının statik ve dinamik dayanıklılığı arasındaki ilişkinin incelenmesi
} Tuğba KOCAHAN ${ }^{1}$, Bihter AKINOĞLU², Tașkın ÖZKAN²

\begin{abstract}
$\ddot{\mathbf{O} z}$
$\mathrm{Bu}$ çalışma, sporcularda statik ve dinamik kor dayanıklılık testlerinin birbirinin yerine kullanılıp kullanılamayacağını değerlendirmek ve bu testler arasındaki ilişkiyi incelemek amacıyla yapıldı. Bu çalıșmaya 1 Ocak-15 Mart 2017 tarihleri arasında Türkiye Olimpiyat Hazırlık Merkezi'ne gelen, onamları alınan ve dahil etme kriterlerine uyan 40 erkek 20 kadın olmak üzere 60 milli (elit) judo sporcusu (Yaș: $17 \pm 3$ yıl; Boy: $169 \pm 8.4 \mathrm{~cm}$; Vücut ağırlığı: $67.7 \pm 16.5 \mathrm{~kg}$; Vücut kitle indeksi: $23.4 \pm 4.4 \mathrm{~kg} / \mathrm{m}^{2}$ ) dahil edildi. Sporcuların kor kaslarının dayanıklılığ 1 , statik ve dinamik olarak değerlendirildi. Kor kaslarının statik dayanıklılığ gövde fleksiyon testi, gövde ekstansiyon testi, sağ ve sol lateral köprü testleri ile değerlendirildi. Testler, test pozisyonu bozulduğunda veya kişi testi devam ettiremeyeceğini söylediğinde sonlandırıldı ve süre kaydedildi. Kor kaslarının dinamik dayanıklılığı sit-ups, modifiye push-ups, sağ ve sol lateral fleksiyon-tekrar testleri ile değerlendirildi. Sporcuların her bir testi 60 saniye boyunca kaç kez yapabildikleri kaydedildi. Milli takım judo sporcularının kor kaslarının statik ve dinamik dayanıklılığı arasındaki ilişki incelendiğinde; gövde fleksiyon testi yalnızca sit-ups testi ile ilişkili bulunurken, diğer tüm statik kor dayanıklılık testleri dinamik kor dayanıklılık testleri ile ilişkili bulundu $(\mathrm{r}=0.260 / 0.500$, $\mathrm{p}<0.05)$. Sonuç olarak, tüm statik ve dinamik kor dayanıklılık parametreleri kendi içerisinde ilișkili bulundu. Birbirinin yerine kullanmayı düșündüğümüz gövde fleksiyon testi/sit-ups testi, gövde ekstansiyon testi/modifiye push-ups testi, sağ lateral köprü testi/sağ lateral fleksiyon-tekrar testi ve sol lateral köprü testi/sol lateral fleksiyon-tekrar testi arasında ilişki bulunmasından dolayı, bu testlerin birbirinin yerine kullanılabileceği düşünülmektedir. Ayrıca bu testlerin birbirinin yerine kullanılabilirliğini test etmek için, diğer spor dallarındaki sporcularda yapılacak çalışmalara da ihtiyaç vardır.
\end{abstract}

Yayın Bilgisi

Anahtar Kelimeler: Dinamik, Judo, Kor dayanıklılık, Spor, Statik

Gönderi Tarihi:26.05.2017

Kabul Tarihi:30.06.2017

Online Yayın Tarihi: 30.09 .2017

DOI: $10.26453 /$ otjhs.315690

Sorumlu Yazar

Taşkın ÖZKAN

\section{The investigation of relationship between static and dynamic endurance of core muscles in athletes}

Tuğba KOCAHAN ${ }^{1}$, Bihter AKINOĞLU², Taşkın ÖZKAN²

\begin{abstract}
The purpose of this study was to evaluate whether static and dynamic core endurance tests could be used in place of each other and to examine the relationship between these tests in athletes. A total of 60 national (elite) team judo athletes, 40 men and 20 women (Age: 17 33 years; Height: $169 \pm 8.4 \mathrm{~cm}$; Body weight: $67.7 \pm 16.5 \mathrm{~kg}$; Body mass index: $\left.23.4 \pm 4 \mathrm{~kg} / \mathrm{m}^{2}\right)$, who came to Turkey Olympic Athletic Educated Center between 1 January-15 March 2017, their verbal approvals were taken and were suited in the inclusion criteria, were included in the study. The endurance of the core muscles of the athletes was evaluated statically and dynamically. Static endurance of the core muscles was evaluated with trunk flexion test, trunk extension test, right and left lateral bridge tests. Tests were terminated when the test position was deteriorated or the person said that he could not continue the test and the time was recorded. Dynamic endurance of the core muscles was evaluated with sit-ups test, modified push-ups test, right and left lateral flexion-repeat tests. It was noted how many times the athletes could perform each test for 60 seconds. When the relationship between the static and dynamic endurance of the core muscles of national team judo athletes was examined; trunk flexion test was only associated with the sit-ups test, all other static core endurance tests were associated with dynamic core endurance tests $(r=0.260 / 0.500, p<0.05)$. In conclusion, all static and dynamic core endurance parameters were related within themselves. Because of the relationship between the trunk flexion test/sit-ups test, trunk extension test/modified push-ups test, right lateral bridge test/right lateral flexion-repeat test and left lateral bridge test/left lateral flexion-repeat test, we think that these tests can be used interchangeably. In addition, there is also a need for studies to be conducted on athletes in other sports to test the usability of these tests for each other.
\end{abstract}

Article Info

Keywords: Dynamic, Judo, Core endurance, Sport, Static

Received:26.05.2017

Accepted:30.06.2017

Online Published: 30.09.2017

DOI: $10.26453 /$ otjhs. 315690

Corresponding Author

Taşkın ÖZKAN

\footnotetext{
${ }^{1}$ Gençlik ve Spor Bakanlığı, Spor Genel Müdürlüğü, Sağlık İşleri Dairesi Başkanlığı, Eryaman, Ankara.

${ }^{2}$ Ankara Yıldırım Beyazıt Üniversitesi, Sağlık Bilimleri Fakültesi, Fizyoterapi ve Rehabilitasyon Bölümü, Ankara.
} 


\section{GíRIŞ}

Kor kasları, ekstremite hareketlerini başlatmak için bir güç merkezi ya da çift duvarlı bir silindir ya da kutu olarak tanımlanmıştır. ${ }^{1} \mathrm{Bu}$ yapının ön kısmını abdominal kaslar, arka kısmını paraspinal kaslar, üst kısmını diyafram ve tabanını kalça kasları ve pelvik taban kasları oluşturmaktadır. ${ }^{1,2}$ Kor stabilite ise, internal ve eksternal bozukluklara karşı vücudun gövdeyi kontrol edebilme yeteneğidir. ${ }^{3}$

Kor kaslarının aktivasyonu ile vücudumuzun merkez anahtar noktası olan gövdede postüral kontrol sağlanır. Yeterli gövde kontrolü, vücut pozisyonunun devam ettirilmesi, pozisyon değiştiğinde stabil kalabilmek, günlük yaşam aktivitelerini yapabilmek ve mobilite fonksiyonu için gereklidir. ${ }^{4-7}$ Kor stabilizasyon ile kalça, pelvis ve omurgada kas ve eklemlerin merkezi yerleşiminden dolayı, proksimalde stabilizasyon sağlanır ve böylece distalde fonksiyonel mobilite ve ektremite hareketleri oluşmaktadır. ${ }^{3-6}$ Ayrıca kor kasları, üst ve alt ekstremiteler arasında enerjinin transferi ve hareketlerin iletilmesinde temel rol oynar. $\mathrm{Bu}$ nedenle spor aktiviteleri sirasında ekstremite hareketleri ve gövde postürünün düzenlenmesi için kor kasların optimal fonksiyonu gerekmektedir. Buna ek olarak, sporcularda atletik yaralanmaların önlenmesinde gövde kaslarının dayanıklılık ve kuvveti kritik öneme sahiptir. ${ }^{6,8-10}$
Panjabi, spinanın stabilitesini pasif, aktif ve nöral kontrol sistemi olarak 3 alt sistemle tanımlamaktadır. ${ }^{11}$ Pasif sistem vertebralar, faset eklemler, intervertebral diskler, processusspinosus, kostalar, annulus ve fibrosus ve ilgili ligamentlerden meydana gelmektedir. $\mathrm{Bu}$ sistem lumbal vertebraların üzerine sadece 9-10kg'llk bir yük ile yüklenilmesine izin vermektedir. $^{2,11}$ Aktif sistem, spinal bölgenin stabilitesi için gerekli kasların oluşturduğu gücü gösterir. Bergmark, stabilizasyonda rol alan bu kasları lokal ve global olmak üzere 2'ye ayırmıştır. Lokal kaslar gövdeyi stabilize eden derin kaslardır. Lokal sistemin primer stabilizatör kasları; M. Transversus abdominis ve M. Multifidus'tur. Sekonder stabilizatör kaslar ise; M. Obliquus internus abdominis, M. Obliquus externus abdominus'un medial lifleri, M. Quadratus lumborum, M. İliocostalis ve M. Longissimus (lumbal bölümleri), $\mathrm{M}$. Diaphragma ve pelvik taban kaslarıdır. Global kas sistemi de temel olarak gövde hareketinin olușturulmasından sorumludur. Gövdenin daha büyük ve yüzeyel kaslarından oluşmaktadır. Global kaslar; M. Obliquus internus abdominis, M. Obliquus externus abdominis'in lateral lifleri, M. Rectus abdominis, M. Quadratus lumborum'un lateral lifleri, M. Psoas major, M. Erector spinae ve gluteal kaslardan oluşmaktadır. 2,11,12 Nöral sistem ise kas iğciği, golgi tendon organı ve omurganın ligamentlerinden sağlanan geribildirimi kullanarak, omurganın stabilizasyonunda 
görevli kasların kuvvetlerini sürekli izler ve ayarlar. Böylece bu kasların kontrol edilmesi sağlanır. ${ }^{11}$

Omurganın aktif stabilitesini sağlayan kor kaslarının dayanıklılığı çeşitli statik ve dinamik testlerle ölçülebilmekte ve bu testler kasın dayanıklılığı hakkında farklı fikirler vermektedir. Statik dayanıklılık kişinin belli bir pozisyonu devam ettirebilme yeteneğini gösterir. Statik dayanıklılık testleri sırasında stabilizasyon ve dinamik dayanıklılık testlerine oranla daha uzun süreli ve daha düşük şiddetli kas aktivasyonu gerekmektedir. Dinamik dayanıklılık, kişinin belli bir süre için de hareketi tekrar edebilme yeteneğini gösterir. Dinamik dayanıklılık testleri sırasında daha çok hareket, sürat, daha büyük kuvvet ve statik dayanıklılık testlerine oranla daha kısa süreli ve yüksek şiddetli kas aktivasyonu gerekmektedir. ${ }^{8,13-15}$ Kas lifi tiplerine baktığımızda ise tip 1 kas liflerinin yavaş kasıldığ1, anaerobik kapasitelerinin düşük olduğu, uzun süreli ve düşük şiddetli aktiviteden sorumlu olduğu, tip 2 kas liflerinin daha büyük kuvvet oluşturduğu, anaerobik kapasitelerinin yüksek olduğu, kısa süreli ve yüksek şiddetli aktiviteden sorumlu olduğu göz önüne alındığında, statik dayanıklılık testlerinde dinamik dayanıklılık testlerine oranla daha çok tip 1 kas liflerinin çalıştığı, dinamik dayanıklılık testlerin de ise statik dayanıklılık testlerine oranla daha çok tip 2 kas liflerinin çalıştığ söylenebilir. Vücudumuzdaki kasları incelediğimizde ise, kaslar yaptıkları kas aktivasyonuna göre farklı oranlarda kas lifi içermektedirler. ${ }^{8,16,17}$

$\mathrm{Bu}$ nedenle çalışmamız, statik ve dinamik kor dayanıklılık testlerinin birbirinin yerine kullanılıp kullanılamayacağını değerlendirmek ve bu testler arasındaki ilișkiyi incelemek amacıyla gerçekleştirildi.

\section{MATERYAL ve METOT}

Çalışma, statik ve dinamik kor dayanıklılık testlerinin birbirinin yerine kullanılıp kullanılamayacağını değerlendirmek ve bu testler arasındaki ilişkiyi incelemek amacıyla gerçekleştirildi Çalışmaya 1 Ocak 2017-15 Mart 2017 tarihleri arasında Türkiye Olimpiyat Hazırlık Merkezi'ne gelen elit judo sporcuları alındı. Son altı ay içerisinde devam eden ağrısı olma, lumbal ve/veya servikal disk hernisi olma, herhangi bir ortopedik problemi olma ve iki yıldan daha kısa süredir spor yapıyor olma dışlama kriterleri olarak belirlendi. Başlangıçta çalışmaya dahil edilen 88 sporcudan 28'i dışlama kriterlerini barındırdığından dolayı çalışma dışı bırakıldı. 40 erkek 20 kadın olmak üzere 60 milli takım judo sporcusu ile çalışma tamamlandı. Çalışmaya katılan sporculara çalışma hakkında bilgi verildi, sporculardan ve antrenörlerinden sözlü onam alındı.

\section{Veri toplama süreci}

Çalışmaya dahil edilen 40'1 erkek (\%66.7), 20'si kadın (\%33.3) toplam 60 sporcunun 
fiziksel özellikleri ve spor yılları Tablo 1'de verildi.

Tablo 1. Sporcuların fiziksel özellikleri ve spor y1lları

\begin{tabular}{|l|c|c|}
\hline & Ortalama \pm SS & Minimum-Maksimum \\
\hline Yaş (yll) & $17 \pm 3$ & $13-24$ \\
\hline Boy uzunluğu (cm) & $169 \pm 8.4$ & $150-188$ \\
\hline Vücut ağırı̆ı̆ı (kg) & $67.7 \pm 16.5$ & $43-138$ \\
\hline Vücut kitle indeksi $\left(\mathbf{k g} / \mathbf{m}^{\mathbf{2}}\right)$ & $23.4 \pm 4$ & $17.7-41.2$ \\
\hline Spor yllı & $8 \pm 3$ & $4-16$ \\
\hline
\end{tabular}

Sporcuların kor kaslarının dayanıklılığı, statik ve dinamik olarak değerlendirildi;

Kor kaslarının statik dayanıklılığı: Kor kaslarının statik dayanıklılığı gövde fleksiyon testi, gövde ekstansiyon testi, sağ ve sol lateral köprü testleri ile değerlendirildi. Ölçümler için kronometre kullanıldı. Sonuçlar saniye cinsinden kaydedildi. Testler, test pozisyonu bozulduğunda veya kişi testi devam ettiremeyeceğini söylediğinde sonlandırıldı. ${ }^{18}$

1. Gövde fleksiyon testi: Sporcular kalça ve dizler $90^{\circ}$, gövde $60^{\circ}$ fleksiyonda ve kollar gövde üzerinde çapraz olacak şekilde pozisyonland1. Değerlendirmeyi yapan fizyoterapist, sporcunun ayakları üzerinden destek verdi ve ayaklarını yere sabitledi. Sporcunun gövde pozisyonu bozulduğunda test sonlandirıldi.

2. Gövde ekstansiyon testi: Sporcular yüzüstü pozisyonda pelvis, kalça ve dizler yatakta olacak ve anterior superior spina iliaka hizasında gövde yataktan dışarıda olacak şekilde pozisyonlandı. Değerlendirme yapan fizyoterapist alt ekstremiteleri stabilize ederken, sporcudan kolları gövde üzerinde çapraz pozisyonda iken gövdenin horizontal pozisyonunu koruması istendi. Sporcunun gövdesi horizontal pozisyonun altına düştüğünde test sonlandırıldı.

\section{Lateral köprü testi: Test sağ ve sol olmak} üzere iki tarafta da değerlendirildi. Sporcular yan yatışta, değerlendirilen taraf kol yere dik, dirsek $90^{\circ}$ fleksiyonda ve önkol yatak üzerinde, üstteki ekstremite gövde üzerinde çapraz olacak şekilde, alt ekstremiteler ekstansiyonda ve üstteki ayak alttaki ayağın önünde olacak şekilde pozisyonlandı. Sporculardan vücutlarını önkolları ve ayak parmakları üzerinde kaldırıp bu pozisyonu korumaları istendi. Sporcular vücudun düz pozisyonunu koruyamadıklarında ve kalça yatağa doğru düştüğünde test sonlandırıld1. ${ }^{18,19}$

Kor kaslarının dinamik dayanıklılı̆ğ: Kor kaslarının dinamik dayanıklılı̆̆ı sit-ups, modifiye push-ups, sağ ve sol lateral fleksiyontekrar testleri ile değerlendirildi. Sporcuların her bir testi 60 saniye boyunca kaç kez yapabildikleri kaydedildi.

1. Sit-ups testi: Sporcular sırtüstü, kalça ve dizler fleksiyonda, kollar gövde üzerinde kenetli iken skapulalar yataktan kalkacak şekilde gövde fleksiyonu yapması ve ardından başlangıç pozisyonuna dönmesi istendi.

2. Modifiye push-ups testi: Sporcular yüzüstü eller omuz genişliğinde olacak şekilde yerde, 
dirsekler tam ekstansiyonda, omuzlar fleksiyonda, dizler fleksiyonda ve birbirine kenetli şekilde pozisyonlandı. Sporculardan kolları yere paralel olacak şekilde gövdelerini yatağa yaklaştırmaları, bu sırada baş ve gövdelerinin pozisyonunu bozmamaları ve ardından başlangıç pozisyonuna dönmeleri istendi.

3. Lateral fleksiyon-tekrar testi: Test sağ ve sol olmak üzere iki tarafta da değerlendirildi. Sporcular yan yatışta, değerlendirilen taraf kol yere dik, dirsek $90^{\circ}$ fleksiyonda ve önkol yatak üzerinde, üstteki ekstremite gövde üzerinde çapraz olacak şekilde, alt ekstremiteler ekstansiyonda ve üstteki ayak alttaki ayağın önünde olacak şekilde pozisyonland. Sporculardan vücutlarını önkolları ve ayak parmakları üzerinde kaldırıp, ardından başlangıç pozisyonuna dönmesi istendi. ${ }^{13-15}$

\section{İstatistiksel Analiz}

Çalışmanın istatistikleri SPSS 15.0 programı kullanılarak yapıldı. Değişkenlerin normal dağılıp dağılmadıklarının tanımlanmaları için görsel (histogram, olasılık grafikleri) ve analitik yöntemler (Kolomogrov-Smirnov/ ShapiroWilk’s testi) kullanıldı. Değişkenler arasındaki ilişkiyi incelemek amacıyla; normal dağılım gösteren sayısal değişkenler için Pearson korelasyon analizi, en az biri normal dağglım göstermeyen değişkenler için Spearman korelasyon analizi kullanıldı. İstatistiksel hata düzeyi $p<0.05$ olarak belirlendi.

\section{BULGULAR}

Statik ve dinamik kor dayanıklılık test sonuçlarının tanımlayıcı istatistikleri Tablo 2'de verildi.

Tablo 2. Statik ve dinamik kor dayanıklılık testlerinin tanımlayıcı istatistikleri

\begin{tabular}{|l|c|c|c|}
\hline & Ortalama $\pm \mathrm{SS}$ & $\begin{array}{c}\text { Minimum } \\
\text { Maksimum }\end{array}$ & $\begin{array}{c}\text { Median } \\
\text { (IQR 25-75) }\end{array}$ \\
\hline $\begin{array}{l}\text { Gövde fleksiyon testi } \\
\text { (saniye) }\end{array}$ & $112.1 \pm 81.7$ & $36-612.2$ & $\begin{array}{c}96.1 \\
(66.3-128.5)\end{array}$ \\
\hline $\begin{array}{l}\text { Gövde ekstansiyon testi } \\
\text { (saniye) }\end{array}$ & $124.4 \pm 40.3$ & $31.8-257.2$ & $\begin{array}{c}123.8 \\
(101.6-142)\end{array}$ \\
\hline $\begin{array}{l}\text { Sağ lateral köprü testi } \\
\text { (saniye) }\end{array}$ & $83.6 \pm 37$ & $26.6-227$ & $\begin{array}{c}76.7 \\
(62.9-98.1)\end{array}$ \\
\hline $\begin{array}{l}\text { Sol lateral köprü testi } \\
\text { (saniye) }\end{array}$ & $93.6 \pm 42.5$ & $26-215.2$ & $\begin{array}{c}86.3 \\
(62.9-116)\end{array}$ \\
\hline $\begin{array}{l}\text { Sit-ups testi } \\
\text { (tekrar sayisı) }\end{array}$ & $61 \pm 8.6$ & $37-78$ & $\begin{array}{c}62 \\
(54.5-66)\end{array}$ \\
\hline $\begin{array}{l}\text { Modifive push-ups testi } \\
\text { (tekrar sayıs1) }\end{array}$ & $56 \pm 18.5$ & $23-99$ & $\begin{array}{c}52.5 \\
(43-73)\end{array}$ \\
\hline $\begin{array}{l}\text { Sağ lateral fleksiyon-tekrar testi } \\
\text { (tekrar sayıs1) }\end{array}$ & $83 \pm 29.6$ & $18-130$ & $\begin{array}{c}84.5 \\
(62-108)\end{array}$ \\
\hline $\begin{array}{l}\text { Sol Lateral fleksivon-tekrar testi } \\
\text { (tekrar sayis1) }\end{array}$ & $91 \pm 29$ & $27-140$ & $\begin{array}{c}93.5 \\
(68-117)\end{array}$ \\
\hline
\end{tabular}

Tablo 3. Sporcuların kor kaslarının statik ve dinamik dayanıklılığı arasındaki ilişki

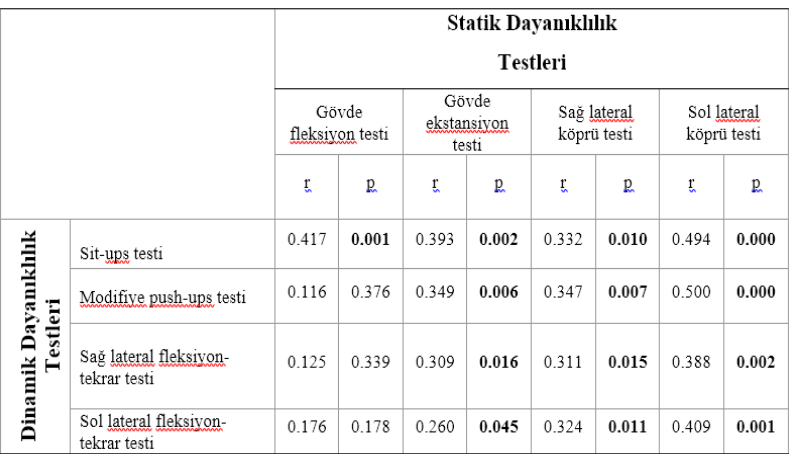

Milli takım judo sporcularının kor kaslarının statik ve dinamik dayanıklılığı arasındaki ilişki incelendiğinde; gövde fleksiyon testi yalnızca sit-ups testi ile ilişkili bulunurken, diğer tüm statik kor dayanıklılı testleri dinamik kor dayanıklılık testleri ile ilişkili bulundu (r= $0.260 / 0.500, \mathrm{p}<0.05)(\underline{\text { Tablo } 3})$ 


\section{TARTIŞMA VE SONUÇ}

Çalışmanın sonucunda, elit judo sporcularında tüm statik ve dinamik kor dayanıklılık testleri kendi içerisinde ilişkili bulundu.

Statik dayanıklılık testleri sirasında stabilizasyon ve dinamik dayanıklılık testlerine oranla daha uzun süreli ve daha düşük şiddetli kas aktivasyonu gerekmektedir. Dinamik dayanıklılık testleri sırasında daha çok hareket, sürat, daha büyük kuvvet ve statik dayanıklılık testlerine oranla daha kısa süreli ve yüksek şiddetli kas aktivasyonu gerekmektedir. Kas lifi tiplerine baktığımızda ise tip 1 kas liflerinin yavaş kasıldığ 1 , anaerobik kapasitelerinin düşük olduğu, uzun süreli ve yüksek şiddetli aktiviteden sorumlu olduğu, tip 2 kas liflerinin daha büyük kuvvet oluşturduğu, anaerobik kapasitelerinin yüksek olduğu, kısa süreli ve yüksek şiddetli aktiviteden sorumlu olduğu göz önüne alındığında, statik dayanıklılık testlerinde dinamik dayanıklılık testlerine oranla daha çok tip 1 kas liflerinin çalıştı̆̆ testlerin de ise statik dayanıklılık testlerine oranla daha çok tip 2 kas liflerinin çalıştı̆̆ söylenebilir. ${ }^{8,13-19}$ Bununla birlikte; judo kısa ve yüksek yoğunluklu eforların tekrarını gerektiren, kısa toparlanma süreleri olan, güç, hız ve kuvvetin farklı kombinasyonlarını gerektiren bir olimpiyat sporudur. ${ }^{20,21}$ Judo sporunu yaparken hareketler sirasında anaerobik mekanizma daha çok etkilidir. Çünkü anaerobik sistem aktivasyonu ile müsabaka sırasında kısa, hızlı ve maksimal güç patlamaları sağlanır.
Bununla birlikte, aerobik sistem de kısa dinlenme periyotları ve eforun azaldığı sırada daha iyi toparlanmaya izin verdiği ve müsabakanın sürekliliğinin sağlanabilmesi için gereklidir. $^{22,23}$ Ayrıca aynı sporu yapan sporcularda Tip 1 ve Tip 2 kas liflerinin dağılımı da benzer olacaktır. Temelde bu nedenlerden dolayı judo sporcularında statik ve dinamik kor dayanıklılıkları arasında ilişki çıktığı düşünülmektedir.

Testler sirasinda aktive olan kaslar incelendiğinde; lateral köprü testleri temel olarak M. Quadratus lumborum ve abdominal duvar gibi lokal kasların, gövde ekstansiyon testi spinanın majör ekstansör kasları olan $\mathrm{M}$. Longissimus ve M. Multifidi gibi lokal kasların, gövde fleksiyon testi temel olarak global bir kas olan M. Rektus abdominis'in aktivasyonunu gerektirir. Sit-ups testinde ise M. Rektus abdominis ve kalça fleksörleri gibi global kasların aktivasyonu gerekir., ${ }^{6,12,18}$ Temelde aynı kasların aktivasyonunu gerektirdiğinden dolayı gövde fleksiyon testi ve sit-ups testi arasında ilişki olması doğaldır. Gövde fleksiyon testi ile diğer dinamik kor testlerinin ilişkili olmamasının nedeninin, testler sirasında temel olarak farklı global kasların kullanılması olduğu düşünülmektedir. Lateral köprü testleri ve gövde ekstansiyon testlerinin dinamik kor dayanıklılık testleri ile ilişkili olmasının nedeninin ise, sporcularda stabilizasyonu ve hareketi sağlayan farklı kas lifi tipleri arasındaki var olan ilişkiden dolayı olduğu 
düşünülmektedir. Literatürü incelediğimizde ise statik ve dinamik kor dayanıklılık arasındaki ilişkiyi inceleyen herhangi bir çalışmanın olmadığı gözlendi. $\mathrm{Bu}$ anlamda bizim çalışmamız özgün nitelik taşımaktadır.

Çalıșmamızda dinamik kor dayanıklılık testleri içerisinde gövde ekstansiyon tekrar testinin olmaması çalışmanın bir limitasyonudur. Diğer bir limitasyon ise sadece judo sporcularının çalışmaya dahil edilip diğer branşlardan sporcuların çalışmaya dahil edilmemesidir.

Sonuç olarak, tüm statik ve dinamik kor dayanıklılık parametreleri kendi içerisinde ilişkili bulundu. Birbirinin yerine kullanmayı düşündüğümüz gövde fleksiyon testi/sit-ups testi, gövde ekstansiyon testi/modifiye push-ups testi, sağ lateral köprü testi/sağ lateral fleksiyontekrar testi ve sol lateral köprü testi/sol lateral fleksiyon-tekrar testi arasında ilişkinin bulunmas1, bu testlerin birbirinin yerine kullanılabileceğini düşündürdü. Ayrıca bu testlerin birbirinin yerine kullanılabilirliğini test etmek için, diğer spor dallarındaki sporcularda yapılacak çalışmalara da ihtiyaç vardır.

\section{KAYNAKLAR}

1. Akuthota V, Nadler SF. Core strengthening. Arch Phys Med Rehabil_2004;85(3):86-92.

2. Richardson C, Jull G, Hodges P, Hides J. Therapeutic Exercise for Spinal Segmental Stabilization in Low Back Pain: Scientific Basis and Clinical Approach. 1st ed. Sydney: Churchill Livingstone; 1999.
3. Borghuis J, Hof AL, Lemmink KA. The importance of sensory-motor control in providing core stability:implications for measurement and training. Sports Med. 2008;38(11):893-916.

4. Cholewicki J, Panjabi MM, Khachatryan A. Stabilizing function of trunk flexor-extensor muscles around a neutral spine posture. Spine. 1997;22(19):2207-12.

5. Ebenbichler GR, Oddsson LI, Kollmitzer J, Erim Z. Sensory-motor control of the lower back: implications for rehabilitation. Med Sci Sports Exerc. 2001;33(11):1889-98.

6. Kibler WB, Press J, Sciascia A. The role of core stability in athletic function. Sports Med. 2006;36(3):189-98.

7. Preuss R, Fung J. Musculature and biomechanics of the trunk in the maintenance of upright posture. J Electromyogr Kinesiol. 2008;18(5):815-28.

8. McGill S. Low Back Disorders: EvidenceBased Prevention and Rehabilitation. 2nd ed. Champaign, IL: Human Kinetics. 2007.

9. Leetun DT, Ireland ML, Willson JD, Ballantyne BT, Davis IM. Core stability measures as risk factors for lower extremity injury in athletes. Med Sci Sports Exerc. 2004;36(6);926-34.

10. Silfies SP, Ebaugh D, Pontillo M, Butowicz CM. Critical review of the impact of core stability on upper extremity athletic injury and performance. Braz J Phys Ther. 2015;19(5):360-8. 
11. Panjabi MM. The stabilizing system of the spine. Part I. Function, dysfunction, adaptation, and enhancement. J Spinal Disord. 1992;5(4):383-9.

12. Bergmark A. Stability of the lumbarspine. A study in mechanical engineering. Acta Orthop Scand Suppl. 1989;230:1-54.

13. Faulkner RA, Sprigings EJ, McQuarrie A, Bell RD. A partial curl-up protocol for adults based on an analysis of two procedures. Canadian journal of sport sciences $=$ Journal canadien des sciences $d u$ sport. 1989;14(3):135-141.

14. Moreland J, Finch E, Stratford P, Balsor B, Gill C. Interrater reliability of six tests of trunk muscle function and endurance. Journal of Orthopaedic \& Sports Physical Therapy 1997; 26(4):200-208.

15. Baltacı G, Bayrakçı Tunay V, Beşler A, Ergun N. Spor Yaralanmalarında Egzersiz Tedavisi. 2 Basım. Ankara: ALP Yayınevi; 2006:102-105.

16. Öner J, Öner H. İskelet kas lifi tipleri. Turkiye Klinikleri J Med Sci. 2004;24:503-7.

17. Lieber RL. Skeletal muscle structure, function, and plasticity. 1st ed. Philadelphia: Lippincott Williams \&Wilkins; 2002.

18. McGill SM, Childs A, Liebenson C. Endurance times for low back stabilization exercises: clinical targets for testing and training from a normal database. Arch Phys Med Rehabil.1999;80(8):941-9.

19. Ambegaonkar JP, Mettinger LM, Caswell SV, Burtt A, Cortes N. Relationships between core endurance, hip strength, and balance in collegiate female athletes. Int $\mathbf{J}$ Sports Phys Ther. 2014;9(5):604-16.

20. Sikorski WG, Mickiewicz G, Maole B, Laska C. Structure of the content and work capacity of the judoists. Polish Judo Association. Warsaw. 1987.

21. Callister R, Callister RJ, Staron RS, Fleck SJ, Tesch P, Dudley GA. Physiological characteristics of elite Judo athletes. Int J Sports Med. 1991;12(2):196-203.

22. Franchini E, Yuri Takito M, Yuzo Nakamura F, Ayumi Matsushigue K, Peduti Dal'Molin Kiss MA. Effects of recovery type after a judo combat on blood lactate removaland on performance in an intermittent anaerobic task. J Sports Med Phys Fitness. 2003;43(4):424-31.

23. Muramatsu S, Horiyasu T, Sato SI, et al. The relationship between aerobic capacity and peak power during intermittent anaerobic exercise of judo athletes. Bulletin of the Association for the Scientific Study on Judo Kodokan. 1994;8:151-60. 
Tablo 1. Sporcuların fiziksel özellikleri ve spor yılları

\begin{tabular}{|l|c|c|}
\hline & Ortalama \pm SS & Minimum-Maksimum \\
\hline Yaş (yıl) & $17 \pm 3$ & $13-24$ \\
\hline Boy uzunluğu (cm) & $169 \pm 8.4$ & $150-188$ \\
\hline Vücut ă̆ırlı̆̆ı (kg) & $67.7 \pm 16.5$ & $43-138$ \\
\hline Vücut kitle indeksi (kg/m $\mathbf{2})$ & $23.4 \pm 4$ & $17.7-41.2$ \\
\hline Spor yılı & $8 \pm 3$ & $4-16$ \\
\hline
\end{tabular}

Tablo 2. Statik ve dinamik kor dayanıklılık testlerinin tanımlayıcı istatistikleri

\begin{tabular}{|l|c|c|c|}
\hline & Ortalama \pm SS & $\begin{array}{c}\text { Minimum } \\
\text { Maksimum }\end{array}$ & $\begin{array}{c}\text { Median } \\
\text { (IQR 25-75) }\end{array}$ \\
\hline $\begin{array}{l}\text { Gövde fleksiyon testi } \\
\text { (saniye) }\end{array}$ & $112.1 \pm 81.7$ & $36-612.2$ & $\begin{array}{c}96.1 \\
(66.3-128.5)\end{array}$ \\
\hline $\begin{array}{l}\text { Gövde ekstansiyon testi } \\
\text { (saniye) }\end{array}$ & $124.4 \pm 40.3$ & $31.8-257.9$ & $\begin{array}{c}123.8 \\
(101.6-142)\end{array}$ \\
\hline $\begin{array}{l}\text { Sağ lateral köprü testi } \\
\text { (saniye) }\end{array}$ & $83.6 \pm 37$ & $26.6-227$ & $\begin{array}{c}76.7 \\
(62.9-98.1)\end{array}$ \\
\hline $\begin{array}{l}\text { Sol lateral köprü testi } \\
\text { (saniye) }\end{array}$ & $93.6 \pm 42.5$ & $26-215.2$ & $\begin{array}{c}86.3 \\
(62.9-116)\end{array}$ \\
\hline $\begin{array}{l}\text { Sit-ups testi } \\
\text { (tekrar sayıs1) }\end{array}$ & $61 \pm 8.6$ & $37-78$ & $\begin{array}{c}62 \\
(54.5-66)\end{array}$ \\
\hline $\begin{array}{l}\text { Modifiye push-ups testi } \\
\text { (tekrar say1s1) }\end{array}$ & $56 \pm 18.5$ & $23-99$ & $\begin{array}{c}52.5 \\
(43-73)\end{array}$ \\
\hline $\begin{array}{l}\text { Sağ lateral fleksiyon-tekrar testi } \\
\text { (tekrar say1s1) }\end{array}$ & $83 \pm 29.6$ & $18-130$ & $\begin{array}{c}84.5 \\
(62-108)\end{array}$ \\
\hline $\begin{array}{l}\text { Sol lateral fleksiyon-tekrar testi } \\
\text { (tekrar sayıs1) }\end{array}$ & $91 \pm 29$ & $27-140$ & $\begin{array}{c}93.5 \\
(68-117)\end{array}$ \\
\hline
\end{tabular}


Tablo 3. Sporcuların kor kaslarının statik ve dinamik dayanıklılığı arasındaki ilişki

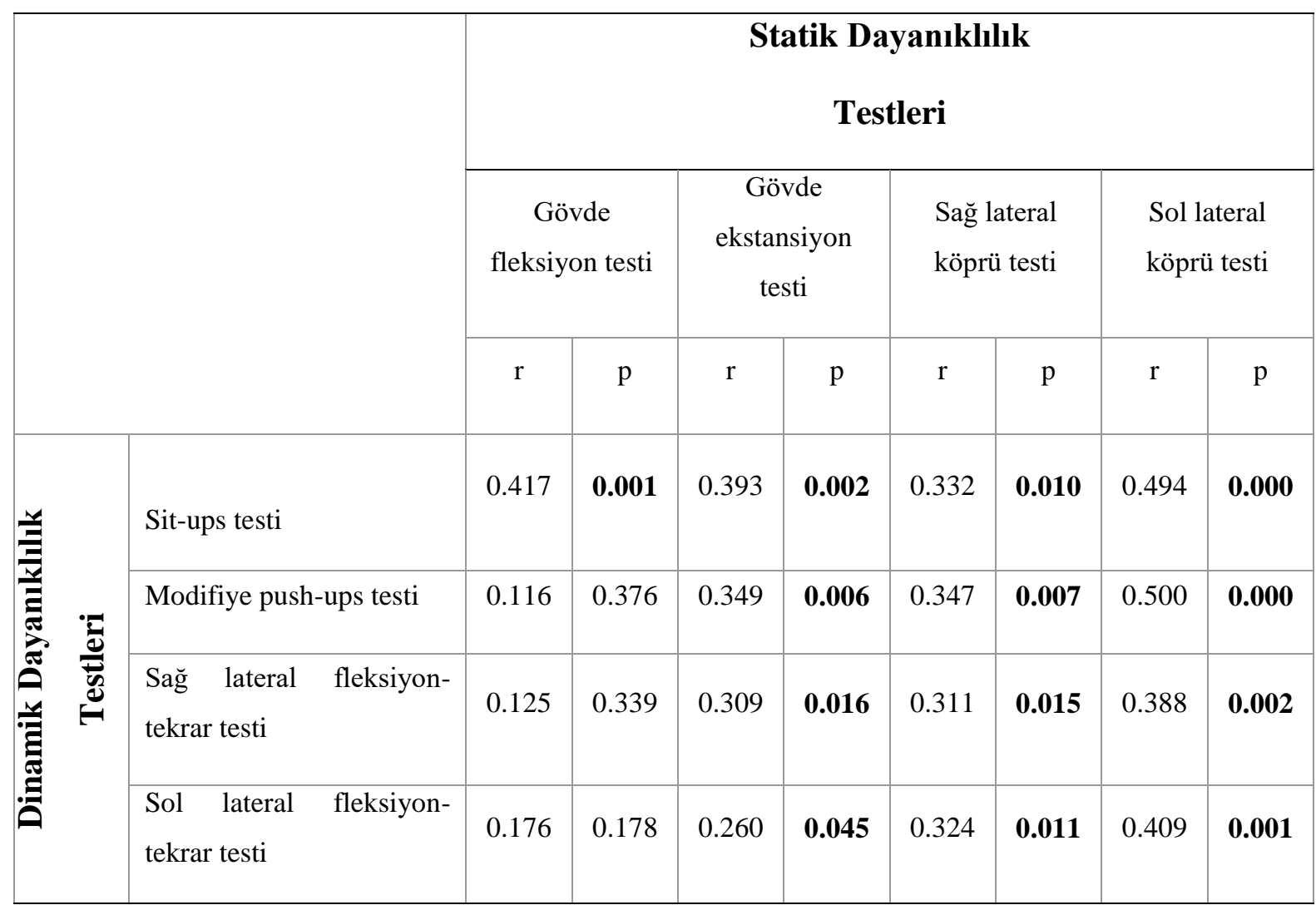

